\title{
Intravesical Toll-like receptor 7 agonist R-837: Optimization of its formulation in an orthotopic mouse model of bladder cancer
}

\author{
Tomoko Hayashi ${ }^{1}$, Brian Crain ${ }^{1}$, Maripat Corr ${ }^{2}$, Michael Chan ${ }^{1}$, Howard B Cottam ${ }^{1}$, Roberto \\ Maj $^{3}$, Alcide Barberis ${ }^{3}$, Lorenzo Leoni ${ }^{3}$, and Dennis A Carson ${ }^{1}$
}

${ }^{1}$ Moores Cancer Center, University of California, San Diego, California, USA ${ }^{2}$ Department of Medicine, University of California, San Diego, California, USA ${ }^{3}$ Telormedix SA, Bioggio, Switzerland

\begin{abstract}
Objective-To study the immune response caused by the intravesical administration of the immunomodulator R-837 in various formulations and to estimate its therapeutic potential for bladder cancer.
\end{abstract}

\begin{abstract}
Methods-Female C57BL/6 mice were intravesically treated with different formulations of R-837, a Toll-like receptor 7 agonist used for treating genital warts and skin malignancy. The tested formulation mixtures contained different ratios of lactic acid, a thermosensitive poloxamer polymer (Lutrol F127) and 2-(hydroxypropyl)- $\beta$-cyclodextrin (HP $\beta C D$ ). Induction of tumor necrosis factor a $(\mathrm{TNFa})$ and keratinocyte-derived chemokine $(\mathrm{KC})$ was analyzed by Luminex microbeads assay. The therapeutic potential of intravesical administration of R-837 was assessed in an orthotopic, syngeneic mouse model of bladder cancer using MB49 cells.
\end{abstract}

Results-Intravesical administration of R-837 in lactic acid alone induced systemic and bladder $\mathrm{TNFa}$ and $\mathrm{KC}$ in a dose-dependent manner. Formulations including poloxamer decreased systemic absorption of R-837 and significantly reduced systemic and local induction of KC. Addition of $\mathrm{HP} \beta C D$ in the poloxamer formulation particularly reversed levels of systemic and local levels of TNFa and KC. Histological examination showed that poloxamer-HP $\beta C D$ formulation allowed infiltration of mononuclear cells into urothelium and lamina propria. In studies using orthotopic mouse bladder cancer, the tumor loads in R-837-treated mice were significantly lower than those in vehicle-treated or non-treated mice.

Conclusion-The optimized poloxamer-HP $\beta \mathrm{CD}$ formulation of R-837 shows therapeutic potential for bladder cancer while avoiding adverse side-effects.

\section{Keywords}

bladder cancer; cyclodextrin; formulation; poloxamer; Toll-like receptor 7 agonist

(c) 2010 The Japanese Urological Association

Correspondence: Tomoko Hayashi, University of California San Diego, Moores Cancer Center, 3855 Health Science Drive, La Jolla, CA 92093-0820, USA. thayashi@ucsd.edu.

Conflict of interest: Roberto Maj and Alcide Barberis are employees of Telormedix. Lorenzo Leoni is a former employee of Telormedix.

Supporting information: Additional supporting information may be found in the online version of this article:

Please note: Wiley-Blackwell are not responsible for the content or functionality of any supporting materials supplied by the authors. Any queries (other than missing material) should be directed to the corresponding author for the article. 


\section{Introduction}

Urinary bladder cancer is the fifth most common malignancy among men in Western society. The majority of bladder cancer cases are diagnosed as non-invasive, superficial tumors that are potentially curable by surgical and immune therapy. ${ }^{1}$ Superficially growing tumors can be removed by transurethral resection but the recurrence rate is high. To prolong the tumor-free intervals after surgical resection, intravesical treatment with Mycobacterium bovis Bacilus-Calmette-Guerin (BCG), the vaccine strain against tuberculosis infection, is currently used as the initial treatment for high-grade superficial tumors (i.e. T1, carcinoma in situ, bulky Ta, or repeated recurrences). ${ }^{2}$

M. bovis BCG treatment induces non-specific local inflammation in the bladder accompanied by various proinflammatory cytokines (interleukin (IL)-2, IL-6, IL-8 and tumor necrosis factor a $(\mathrm{TNFa}))^{3}$ and chemokines, that in turn initiate infiltration of immune cells in the bladder urothelium. ${ }^{4,5}$ BCG instillation causes non-specific stimulation of the immune system, which induces local infiltration of the bladder wall by activated $\mathrm{T}$ cells derived by cell mediated immunity. ${ }^{6}$

R-837, a Toll-like receptor 7 (TLR7) agonist, is a potent immune modulator currently used as a first-line topical therapy for genital warts and superficial basal cell carcinomas. ${ }^{7-9}$ In addition, R-837 has been used for the treatment of malignant skin lesions including melanoma and basal cell carcinoma. ${ }^{9} \mathrm{R}-837$ induces proinflammatory cytokines and chemokines in vitro and in vivo ${ }^{10}$ that attract immune cells to the local site of administration. ${ }^{11}$ Imidazoquinolines have been shown to direct cytotoxic effects to bladder cancer cells and induce them to secrete proinflammatory cytokines. ${ }^{12}$ It is further descried that imidazoquinolines have anti-tumor effects in orthotopic bladder cancer mouse models. ${ }^{12}$ The objective of the present study was to optimize the formulation of R-837 to improve therapeutic application. The systemic and local inflammation induced by various formulations of R-837 was compared. The anticancer efficacy of R-837 in thermosensitive poloxamer polymer was evaluated in murine orthotopic bladder cancer models.

\section{Methods}

Mice

Six- to 8-week old female C57BL/6 mice were purchased from Charles River Laboratory (Wilmington, MA, USA). TLR7-deficient mice were a gift from S. Akira (Osaka University, Osaka, Japan) and backcrossed for 10 generations onto the C57BL/6 background mice. All mice were housed under standard conditions in the University of California, San Diego (UCSD) Animal Facility. All procedures and protocols received prior approval by the Institutional Review Board of UCSD.

\section{Reagents}

R-837 and Lutrol F127 (Fig. S1) were provided by Telormedix SA (Bioggio, Switzerland). Lactic acid was purchased from Fisher Scientific (Pittsburgh, PA, USA). 2-(hydroxypropyl)$\beta$-cyclodextrin (HP $\beta C D$ ) was purchased from Sigma Aldrich (St Louis, MO, USA) (Fig. S1). R-837 was dissolove at the final concentration of $1 \%(\mathrm{w} / \mathrm{v}, 41.7 \mathrm{mM})$ in $0.1 \%$ lactic acid (lactic acid formulation). Lutrol F127 was added to $0.1 \mathrm{M}$ lactic acid to make $20 \%$ (poloxamer formulation). 5\% HPßCD was incorporated into 15\% Lutrol F127, in $0.1 \mathrm{M}$ lactic acid (poloxamer-HP $\beta C D$ formulation). All solutions were filtered by $0.22 \mu \mathrm{m}$ filter before administration. 


\section{In vivo pharmacological study}

Mice were anesthetized with Ketamin- $\mathrm{HCl}(100 \mathrm{mg} / \mathrm{kg})$ and xylazine hydrochloride $(10 \mathrm{mg} /$ $\mathrm{mL}$ ) and catheterized using a $20 \mathrm{G}$ Teflon intravenous catheter (Terumo Co. Somerset, NJ, USA). One hundred and fifty, 500 or 1500 nmoles R-837 in 50 or $100 \mu \mathrm{L}$ vehicles were intravesically administered, respectively. One hundred and twenty $\mu \mathrm{L}$ volume was used for installation of 5000 nmoles. The R-837 solution was kept in the bladder for $20 \mathrm{~min}$. In preliminary experiments, we compared serum cytokine levels at $2 \mathrm{~h}$ post-administration of 20-min and 60-min instillation periods using R-837 in lactic acid formulation. There was no significant difference in serum levels of TNFa and KC between the 20-min and 60-min instillation period. Therefore, a 20-min instillation time was used in the present study. At the various time points, serum and bladder lavage were collected. The bladder lavage was collected following administration of $100 \mu \mathrm{L}$ saline. The levels of cytokines were measured by Luminex microbead assay (Invitrogen, Carlsbad, CA, USA) according to the manufacturer's instruction. The minimum detection levels of TNFa, and $\mathrm{KC}$ were $5 \mathrm{pg} / \mathrm{mL}$ and $25 \mathrm{pg} / \mathrm{mL}$, respectively. Total cytokines per bladder was calculated by instillation volume $(0.1 \mathrm{~mL}) \times($ concentration of $\mathrm{TNFa}$ or $\mathrm{KC} / \mathrm{mL}$ lavage). The level of $\mathrm{R}-837$ in serum was analyzed by Chiman SRL (Rottofreno, Italy), a contract laboratory. Briefly, R-837 and metabolites were extracted from serum and quantified using high performance liquid chromatography on a reversed phase C8 column with ultraviolet detection at $242 \mathrm{~nm}$.

\section{Histological examination}

Mice were administered $100 \mu \mathrm{L} 0.1 \% \mathrm{R}-837$ in poloxamer-HP $\beta \mathrm{CD}$ formulation once, or 50 $\mu \mathrm{L}$ three times at four-day intervals. At $24 \mathrm{~h}$ after the last administration, the bladders were collected. The fixed bladders were paraffin-embedded and stained with hematoxylin-eosin (HE) by UCSD Cancer Center Histology Core.

\section{Implantation, treatment and assessment of tumor}

C57BL/6 mice were anaesthetized and treated with $100 \mu \mathrm{L}$ of $0.1 \mathrm{mg} / \mathrm{mL}$ poly-L-lysine for 20 min to enhance tumor cell adhesion. ${ }^{13,14}$ After treatment with poly-L-lysine, $1 \times 10^{6}$ MB49 cells were implanted, as described previously. ${ }^{13-15}$ The treatment was performed on days 3, 6 and 9. MB49-implanted mice with no treatment or vehicle treatment served as controls. Mice were killed on day 11 and the weight of bladder was measured. ${ }^{14}$

\section{Statistical analysis}

A software package (Prism 4.0, GraphPad, San Diego CA, USA) was used for statistical analyses as indicated in the figure legends. The statistical differences were analyzed by unpaired Student- $t$-test to compare two groups and one-way anova to compare multiple groups. In the one-way anova, Dunnett's post hoc testing was used to compare the value to the control group and Bonferroni's post hoc testing was used to compare multiple groups to each other. A value of $P<0.05$ was considered statistically significant.

\section{Results}

\section{Intravesical administration of R-837 induced systemic inflammation}

$\mathrm{R}-837$ is known to be insoluble in water and sparingly soluble in common pharmaceutical solvents. Because acid solution increases the solubility of R-837, ${ }^{16} 0.1 \mathrm{M}$ lactic acid was used to prepare 1\% R-837 solution $(\sim 41.7 \mathrm{mM})$. Mice intravesically received 150, 500, 1500 and 5000 nmoles. Serum TNFa and KC were induced in a dose-dependent manner (0.1 M lactic acid in Fig. 1a,b). The levels of these factors in the bladder lavages were 10100 times lower than the levels in their serum $(P<0.001$ at 1500 and 5000 nmoles, Fig. $1 \mathrm{c}, \mathrm{d})$. 


\section{Addition of poloxamer polymer prevented absorption of R-837 and systemic induction of cytokines}

Systemic induction of proinflammatrory cytokines causes anorexia and fatigue, so called 'sickness syndrome' in hosts. ${ }^{17}$ To avoid systemic absorption as well as increase the local contact of R-837 to the urothelium, thermosensitive poloxamer polymer, Lutrol F127, was added to the formulation. The levels of TNFa (Fig. 2a,b) and KC (Fig. 2c,d) in both serum and bladder were significantly reduced in mice that received 5000 nmoles of R-837 in this formulation compared with the formulation with lactic acid.

To evaluate the effects of the poloxamer polymer on the systemic absorption of R-837 via bladder urothelium, the sera from mice that received 1500 nmoles R- 837 were collected at 2 , 4, 6, 24 and $48 \mathrm{~h}$. In mice receiving R-837 either in lactic acid alone or in poloxamer formulation, maximum serum concentration of R- 837 was observed $2 \mathrm{~h}$ after administration (Fig. 2e) $(P<0.01)$. The levels of serum R-837 increased in a dose-dependent manner (Fig. $2 \mathrm{f})$. Addition of poloxamer polymer in the formulation reduced the serum levels of R-837 at $2 \mathrm{~h}$ time points $(P<0.01$, Fig. $2 \mathrm{e})$ and at 5000 nmoles $(P<0.01$, Fig. $2 \mathrm{f})$. These data indicate that inclusion of poloxamer in the formulation significantly reduces systemic absorption of R-837.

\section{Incorporation of HPßCD restores systemic and local inflammation}

To improve physical stability and achieve complete release from the poloxamer polymer, R-837 was incorporated with HP $\beta C D$ to poloxamer in lactic acid (poloxamer-HP $\beta C D$ formulation). The systemic levels of TNFa and $\mathrm{KC}$ were evaluated and compared with the other formulations (Fig. 3). Adding the poloxamer polymer reduced the serum $\mathrm{KC}$ levels to almost baseline levels, compared with lactic acid formulation $(P<0.001$, Fig. 3a,b). Addition of $\mathrm{HP} \beta \mathrm{CD}$ to the poloxamer formulation significantly restored the serum $\mathrm{KC}$ level (Fig. 3b), but not TNFa (Fig. 3a). A similar trend was seen in local levels of KC (Fig. 3c).

\section{Evaluation of local inflammation in the bladder by intravesical administration of R-837 in poloxamer-HPßCD formulation}

To evaluate local inflammation in the bladder, mice received intravesically $0.1 \% \mathrm{R}-837$ in poloxamer-HP $\beta C D$ formulation as vehicle. Influx of inflammatory cells in the bladder was evaluated by histological examination (Fig. 4). Because patients received repeated intravesical treatments in the clinical application, we tested the effect of repeated administration of R-837 in poloxamer-HP $\beta \mathrm{CD}$ formulation on days 0,4 and 8 . After the first instillation of R-837, the cell infiltration was initiated (Fig. 4c) compared with the vehicle alone (Fig. 4a). After the third treatment, substantial infiltration of mononuclear cells in the lamina propria in the bladder treated with R-837 was observed (Fig. 4d), while few cells infiltrated in the vehicle- or saline-treated bladders (Fig. 4b,e). Reduced cell infiltration was observed in the bladder of TLR7 deficient mice treated with R-837 in poloxamer-HP $\beta C D$ formulation similar to saline-treated mice, indicating that inflammation induced by R- 837 in the bladder was TLR7 dependent (Fig. 4f).

\section{Evaluation of inhibition of local tumor growth of R-837 in poloxamer-HP $\beta C D$ formulation in mouse orthotopic bladder cancer models}

Orthotopic bladder tumor models were generated using MB49, a cell line derived from transitional cell carcinoma of the murine urinary tracts. Mice bearing the MB49 bladder tumor were treated three times (days 3, 6 and 9) with $50 \mu \mathrm{L}$ of $0.1 \% \mathrm{R}-837$ in poloxamer$\mathrm{HP} \beta C \mathrm{CD}$ formulation as vehicle. The treatment group showed significantly lower average tumor loads compared with the non-treated or vehicle-treated group $(P<0.01$, Fig. 5). Thus, 
treatment with R-837 in poloxamer-HP $\beta C D$ formulation maintained the bladder weight to nearly that of non-tumor bearing (naïve) mice.

\section{Discussion}

R-837, a specific TLR7 agonist, is currently approved for treatment of skin disorders such as viral warts and superficial basal cell carcinomas. ${ }^{7,8} \mathrm{R}-837$ directly inhibits tumor growth and has potent therapeutic activity in superficial bladder cancer. ${ }^{18}$ In the present study, thermosensitive poloxamer polymer was used to ensure prolonged local contact and minimize systemic absorption of R-837. Polymer formulation reduced systemic absorption of R-837 from bladder urothelium with enhanced local infiltration of immune cells. Incorporating $\mathrm{HP} \beta C D$ in the formulation improved the physical stability, achieving a clear homogeneous solution. This formulation improved the induction of local chemokine and showed anti-tumor effects in an orthotopic mouse model of bladder cancer.

Intravesical BCG administration is a well established immune therapy of superficial bladder cancer. ${ }^{19}$ Although live BCG bacilli provides a significant advantage to evoke the immune response, use of live BCG requires careful biohazard precaution for health care staff and patients. ${ }^{20}$ BCG remains only partially effective and serious side-effects, including high fever, pneumonia, hepatitis and sepsis, might occur. Efforts to develop safer and more effective therapy for bladder cancer continue. Among those, attempts to use the individual TLR agonist to treat bladder cancer have been reported. ${ }^{12,14,21}$ Repeated application of the TLR9 agonist improved survival and reduced tumor loads. ${ }^{21}$ TLR7 agonist R-837 directly affects human and mouse bladder cancer cells to induce chemokine secretion, and to induce apoptosis and reduce tumor growth. ${ }^{12}$ We showed in the present study that R-837 in poloxamer-HP $\beta C D$ formulation could initiate a substantial local innate immune reaction.

Because acid formulation increased solubility of R-837, we initially tested R-837 dissolved in $0.1 \mathrm{M}$ lactic acid that is commonly used in the pharmaceutical industry. R-837 in lactic acid formulation was absorbed systemically and caused significant induction of systemic inflammation. Live BCG bacilli adhere to the surface of the bladder wall, ${ }^{22,23}$ and provide sustained immune stimulation to urothelium and local immune cells for prolonged periods. Thermosensitive poloxamer polymer reduces the drug release and holds the drug concentration on the surface of the cells, and prevents systemic absorption of the drug. ${ }^{24}$ To recapitulate the advantageous pro-inflammatory properties of live BCG bacilli infection and to reduce the systemic absorption, as well as increase the surface contact of the drug, thermosensitive poloxamer polymer was added to the lactic acid formulation. The poloxamer formulation significantly reduced the systemic absorption of R-837 through the bladder surface and reduced the systemic cytokine induction to baseline levels.

The component of the present study that was of particular interest was that the formulation including $\mathrm{HP} \beta C D$ restored the induction of $\mathrm{KC}$ by $\mathrm{R}-837$ compared with that of poloxamer alone. Complexation using $\mathrm{HP} \beta \mathrm{CD}$ is a common approach for increasing drug solubility and stability in aqueous media. ${ }^{25,26}$ Moreover, inclusion of $\mathrm{HP} \beta C D$ in polymers is used in vaginal delivery systems. ${ }^{27}$ Because $20 \%$ thermosensitive poloxamer was observed to solidify in the bladder within a short time, causing obstruction of the urethra, the concentration of poloxamer was reduced to $15 \%$. Specifically, incorporating $\mathrm{HP} \beta C D$ in the polymer in an orthoptropic mouse model of bladder cancer.

Effective anti-tumor immune therapy requires appropriate recruitment of immune cells. ${ }^{5,28}$ Histological examination shows substantial immune cell infiltration into the submucosal space (i.e. the lamina propria) by R-837, similar to that found following intravesical administration of TLR9 agonists. ${ }^{14}$ Cell infiltration in the bladder induced by R-837 
diminished in TLR7-deficient mice, indicating the inflammation was TLR7 dependent, not caused by vehicle or mechanical injury. The integrity of the urothelium was well maintained after repeated administration of vehicle alone (poloxamer-HP $\beta C D$ formulation). ${ }^{10,29}$

In summary, our results suggest the formulation of poloxamer and $\mathrm{HP} \beta C D$ of drugs with low solubility might exert favorable properties, such as a slow release profile and longer surface contact, while avoiding possible systemic adverse effects. Optimized poloxamer$\mathrm{HP} \beta \mathrm{CD}$ formulations might increase the maximum tolerated dose of R-837 and improve patient compliance.

\section{Supplementary Material}

Refer to Web version on PubMed Central for supplementary material.

\section{Acknowledgments}

This work was supported by a research grant from Telormedix. The authors acknowledge the important contributions of Christine Gray for technical assistance to perform the experiments. Tomoko Hayashi has full access to all data in this study and takes responsibility for the integrity and accuracy of the data and their analysis. Roberto Maj, Alcide Barberis and Lorenzo Leoni contributed to the selection of formulation and refinement of the discussion of the manuscript and had no role in the design and conduct of the study.

\section{References}

1. Schenk-Braat EA, Bangma CH. Immunotherapy for superficial bladder cancer. Cancer Immunol Immunother. 2005; 54:414-23. [PubMed: 15565330]

2. Oosterlinck W, Lobel B, Jakse G, Malmstrom PU, Stockle M, Sternberg C. Guidelines on bladder cancer. Eur Urol. 2002; 41:105-12. [PubMed: 12074395]

3. De Boer EC, Rooijakkers SJ, Schamhart DH, Kurth KH. Cytokine gene expression in a mouse model: the first instillations with viable bacillus Calmette-Guerin determine the succeeding Th1 response. J Urol. 2003; 170:2004-8. [PubMed: 14532842]

4. Suttmann H, Riemensberger J, Bentien G, et al. Neutrophil granulocytes are required for effective Bacillus Calmette-Guerin immunotherapy of bladder cancer and orchestrate local immune responses. Cancer Res. 2006; 66:8250-7. [PubMed: 16912205]

5. Simons MP, O'Donnell MA, Griffith TS. Role of neutrophils in BCG immunotherapy for bladder cancer. Urol Oncol. 2008; 26:341-5. [PubMed: 18593617]

6. Bohle A, Brandau S. Immune mechanisms in bacillus Calmette-Guerin immunotherapy for superficial bladder cancer. J Urol. 2003; 170:964-9. [PubMed: 12913751]

7. Purdon CH, Azzi CG, Zhang J, Smith EW, Maibach HI. Penetration enhancement of transdermal delivery - current permutations and limitations. Crit Rev Ther Drug Carrier Syst. 2004; 21:97-132. [PubMed: 15202928]

8. Chang YC, Madkan V, Cook-Norris R, Sra K, Tyring S. Current and potential uses of imiquimod. South Med J. 2005; 98:914-20. [PubMed: 16217984]

9. Wagstaff AJ, Perry CM. Topical imiquimod: a review of its use in the management of anogenital warts, actinic keratoses, basal cell carcinoma and other skin lesions. Drugs. 2007; 67:2187-210. [PubMed: 17927284]

10. Chan M, Hayashi T, Kuy CS, et al. Synthesis and immunological characterization of toll-like receptor 7 agonistic conjugates. Bioconjug Chem. 2009; 20:1194-200. [PubMed: 19445505]

11. Barnetson RS, Satchell A, Zhuang L, Slade HB, Halliday GM. Imiquimod induced regression of clinically diagnosed superficial basal cell carcinoma is associated with early infiltration by CD4 T cells and dendritic cells. Clin Exp Dermatol. 2004; 29:639-43. [PubMed: 15550144]

12. Smith EB, Schwartz M, Kawamoto H, et al. Antitumor effects of imidazoquinolines in urothelial cell carcinoma of the bladder. J Urol. 2007; 177:2347-51. [PubMed: 17509356] 
13. Hegele A, Dalpke A, Heeg K, et al. Immunostimulatory CpG oligonucleotides reduce tumor burden after intravesical administration in an orthotopic murine bladder cancer model. Tumour Biol. 2005; 26:274-80. [PubMed: 16103747]

14. Olbert PJ, Schrader AJ, Simon C, et al. In vitro and in vivo effects of CpG-Oligodeoxynucleotides (CpG-ODN) on murine transitional cell carcinoma and on the native murine urinary bladder wall. Anticancer Res. 2009; 29:2067-76. [PubMed: 19528466]

15. Hegele A, Dalpke A, Barth P, et al. Antineoplastic effect of immunostimulatory DNA (CpG-ODN) in a murine C57-BL6/MB-49 transitional cell carcinoma model. Anticancer Res. 2004; 24:222530. [PubMed: 15330165]

16. Chollet JL, Jozwiakowski MJ, Phares KR, et al. Development of a topically active imiquimod formulation. Pharm Dev Technol. 1999; 4:35-43. [PubMed: 10027211]

17. Hayashi T, Cottam HB, Chan M, et al. Mast cell-dependent anorexia and hypothermia induced by mucosal activation of Toll-like receptor 7. Am J Physiol Regul Integr Comp Physiol. 2008; 295:R123-32. [PubMed: 18480244]

18. Liu H, Schwartz MJ, Hwang DH, Scherr DS. Tumour growth inhibition by an imidazoquinoline is associated with c-Myc down-regulation in urothelial cell carcinoma. BJU Int. 2008; 101:894-901. [PubMed: 18241249]

19. Alexandroff AB, Jackson AM, O'Donnell MA, James K. BCG immunotherapy of bladder cancer: 20 years on. Lancet. 1999; 353:1689-94. [PubMed: 10335805]

20. Games J. Nursing implications in the management of superficial bladder cancer. Semin Urol Oncol. 1996; 14:36-40. [PubMed: 8727809]

21. Mangsbo SM, Ninalga C, Essand M, Loskog A, Totterman TH. CpG therapy is superior to BCG in an orthotopic bladder cancer model and generates CD4+ T-cell immunity. J Immunother. 2008; 31:34-42. [PubMed: 18157010]

22. Atkins H, Davies BR, Kirby JA, Kelly JD. Polarisation of a T-helper cell immune response by activation of dendritic cells with $\mathrm{CpG}$-containing oligonucleotides: a potential therapeutic regime for bladder cancer immunotherapy. Br J Cancer. 2003; 89:2312-19. [PubMed: 14676812]

23. Akazawa T, Masuda H, Saeki Y, et al. Adjuvant-mediated tumor regression and tumor-specific cytotoxic response are impaired in MyD88-deficient mice. Cancer Res. 2004; 64:757-64. [PubMed: 14744795]

24. Anderson BC, Pandit NK, Mallapragada SK. Understanding drug release from poly(ethylene oxide)-b-poly(propylene oxide)-b-poly(ethylene oxide) gels. J Control Release. 2001; 70:157-67. [PubMed: 11166416]

25. Brewster ME, Loftsson T. Cyclodextrins as pharmaceutical solubilizers. Adv Drug Deliv Rev. 2007; 59:645-66. [PubMed: 17601630]

26. Bilensoy E, Rouf MA, Vural I, Sen M, Hincal AA. Mucoadhesive, thermosensitive, prolongedrelease vaginal gel for clotrimazole:beta-cyclodextrin complex. AAPS PharmSciTech. 2006; 7:E38. [PubMed: 16796356]

27. Chang JY, Oh YK, Kong HS, et al. Prolonged antifungal effects of clotrimazole-containing mucoadhesive thermosensitive gels on vaginitis. J Control Release. 2002; 82:39-50. [PubMed: 12106975]

28. Saban MR, Simpson C, Davis C, et al. Discriminators of mouse bladder response to intravesical Bacillus Calmette-Guerin (BCG). BMC Immunol. 2007; 8:6. [PubMed: 17506885]

29. Luo Y, Chen X, O'Donnell MA. Role of Th1 and Th2 cytokines in BCG-induced IFN-gamma production: cytokine promotion and simulation of BCG effect. Cytokine. 2003; 21:17-26. [PubMed: 12668155] 
(a)

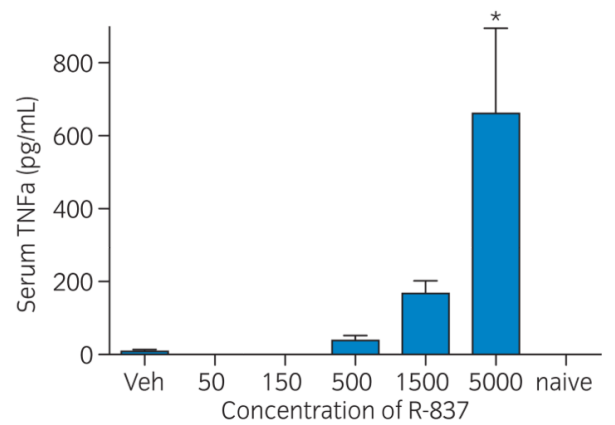

(c)

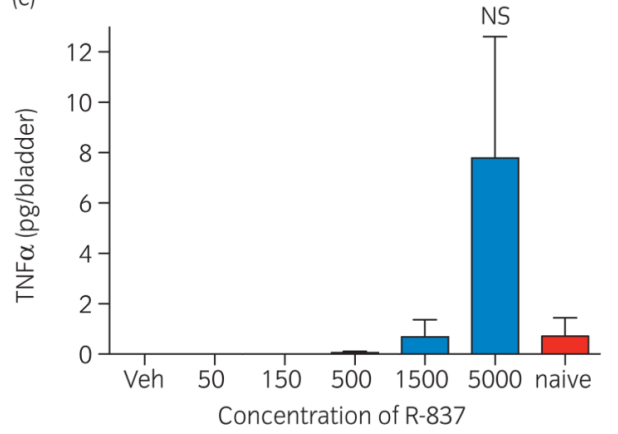

(b)

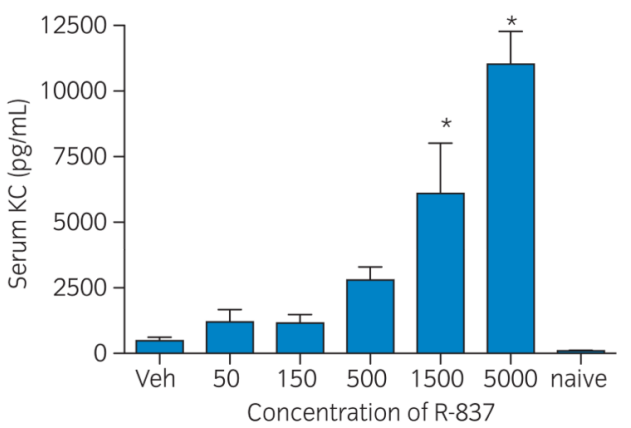

(d)

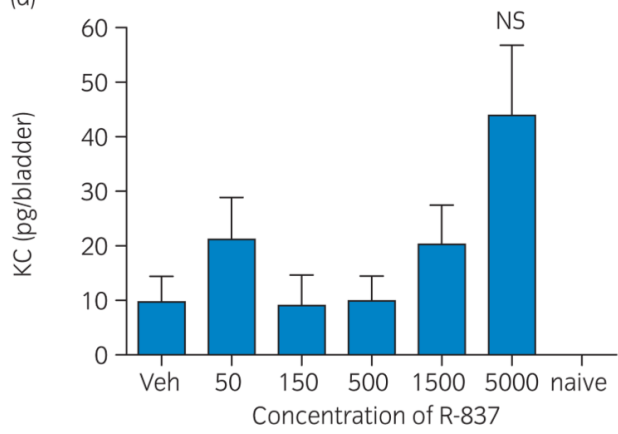

Fig. 1.

Cytokine and chemokine induction in serum and bladder lavage by intravesical administration of R-837 in $0.1 \%$ lactic acid or poloxamer in $0.1 \mathrm{M}$ lactic acid. Mice $(n=8)$ intravesically received various doses of R-837 in lactic acid formulation. Two hours after administration, sera and bladder lavage were collected. The levels of tumor necrosis factor a (TNFa) (a) and keratinocyte-derived chemokine (KC) (b) in serum, and TNFa (c) and KC (d) in the bladder lavage were measured. *Statistically significant. NS, not significant; Veh, vehicle. 

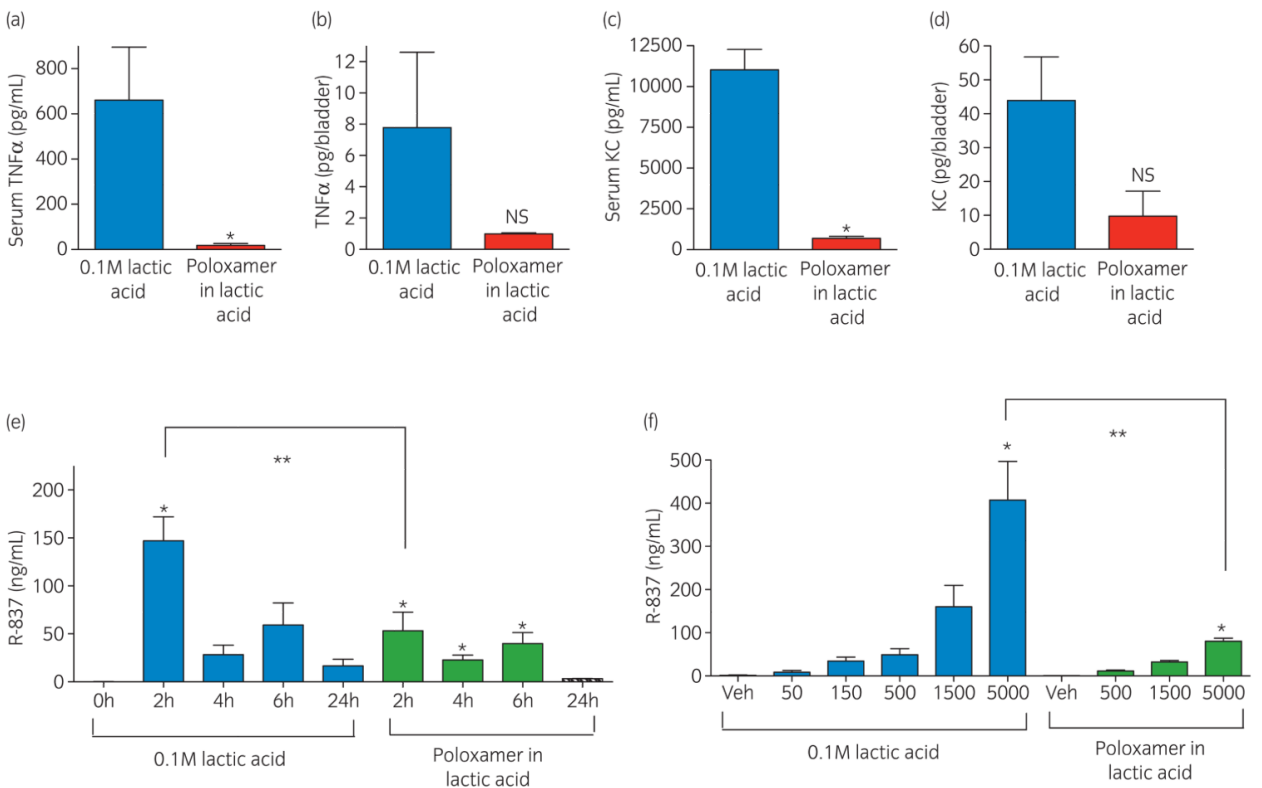

Fig. 2.

Pharmacokinetics of R-837 in mice after intravesical administration. (a-d) Mice $(n=8)$ were administered 5000 nmoles R-837 in lactic acid or poloxamer formulation. The levels of serum tumor necrosis factor a (TNFa) (a), TNFa in bladder lavage (b), serum keratinocytederived chemokine (KC) (c), and $\mathrm{KC}$ in bladder lavage (d) were measured. *Statistically significant. NS, not significant. (e) Mice $(n=6-8)$ were administered 1500 nmoles R-837 in lactic acid or poloxamer formulation. Sera were collected 2, 4, 6 and $24 \mathrm{~h}$ after administration. (f) Mice $(n=6)$ were administered various doses of R-837 in $100 \mu \mathrm{L}$ in lactic acid or poloxamer formulations. Sera were collected 2-4 $\mathrm{h}$ after administration. The levels of R-837 were determined by Chiman SRL. Data shown are pooled values from two independent experiments (mean \pm SEM.).*,**Statistically significant. NS, not significant compared with treated mice at $0 \mathrm{~h}$ time point or mice treated with vehicle (Veh) alone. 

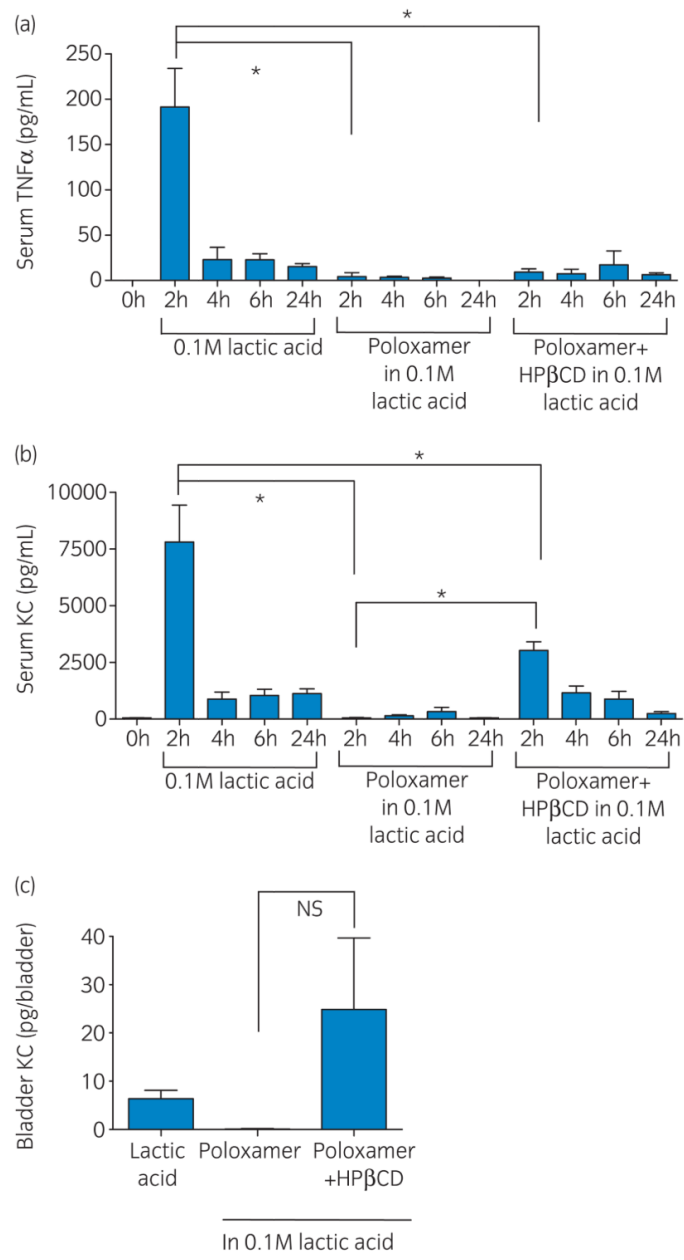

Fig. 3.

Incorporation of 2-(hydroxypropyl)- $\beta$-cyclodextrin (HP $\beta C D)$ partially restores systemic tumor necrosis factor $\mathrm{a}(\mathrm{TNFa})$ and keratinocyte-derived chemokine $(\mathrm{KC})$ levels. Mice $(n=$ 8) were administered 1500 nmoles R-837 in lactic acid, poloxamer or poloxamer-HP $\beta C D$ formulation. The levels of TNFa (a) and KC (b) are shown. Data presented are pooled values from two independent experiments (mean \pm SEM). *Statistically significant. (c) C57BL/6 mice were injected with 5000 nmoles R-837 in lactic acid, poloxamer or poloxamer-HP $\beta \mathrm{CD}$ formulations. The levels of $\mathrm{KC}$ in the lavage were assessed by Luminex beads assay. NS, not significant $(P>0.05)$. 


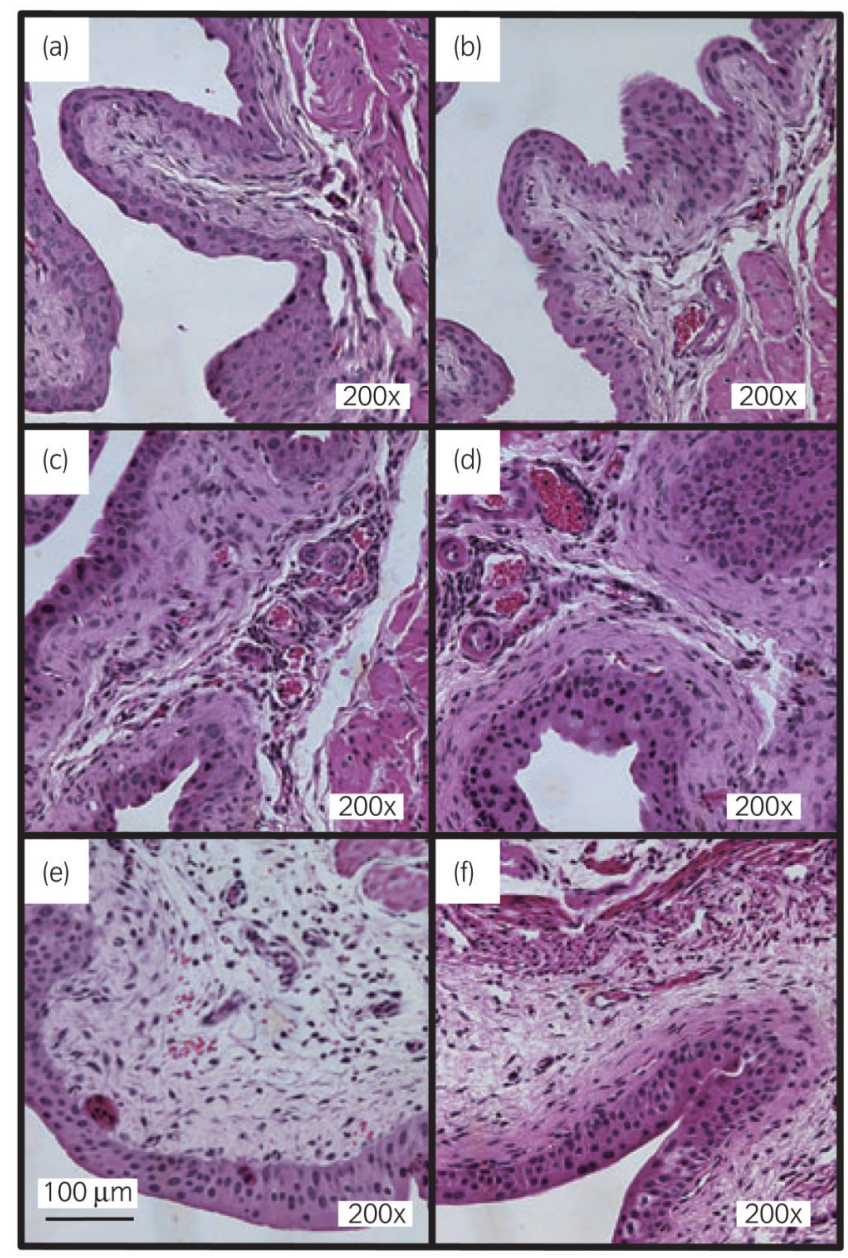

Fig. 4.

Representative histology of murine bladder treated with $0.1 \% \mathrm{R}-837$ in poloxamer-2(hydroxypropyl)- $\beta$-cyclodextrin (HP $\beta C D$ ) formulation. C57BL/6 (a-e) or Toll-like receptor 7 (TLR7) deficient mice (ko) (f) were intravesically treated with $0.1 \%$ R-837 in poloxamerHP $\beta C D$ formulation on day 0 (single treatment), $50 \mu \mathrm{L}$ on days 0,4 and 8 (three times treatment). The bladders were collected on day 1 for single treatment (a and c) or on day 9 for three times treatment (b, d, e and f) and stained with HE. Mice treated with vehicle (Veh) alone and naïve mice served as controls (b and e). (a) Single treatment Veh (wild type C57BL/6). (b) Three times treatment Veh (wild type C57BL/6). (c) Single treatment R-837 (wild type C57BL/6). (d) Three times treatment R-837 (wild type C57BL/6). (e) Three times treatment saline (wild type C57BL/6). (f) Three times treatment R- 837 (TLR7 ko). Scale bar, $100 \mu \mathrm{m}$. Original magnification, $\times 200$. 


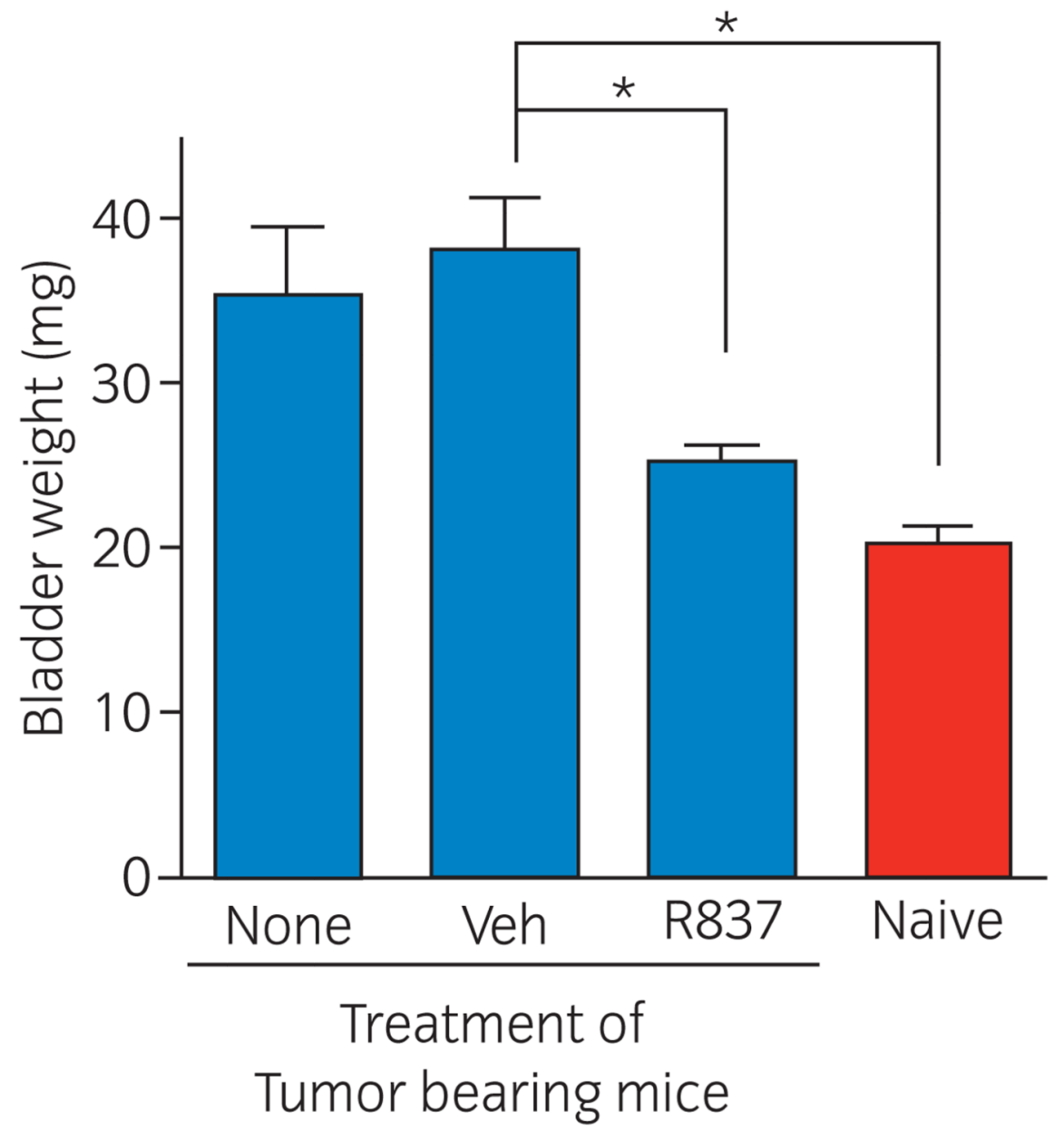

Fig. 5.

Reduced bladder weight of mice bearing MB49 treated $0.1 \% \mathrm{R}-837$ in poloxamer-2(hydroxypropyl)- $\beta$-cyclodextrin (HP $\beta C D)$ formulation. Mice $(n=11)$ bearing MB49 bladder tumor intravesically received $50 \mu \mathrm{L} 0.1 \% \mathrm{R}-837$ in poloxamer-HP $\beta \mathrm{CD}$ formulation on days 3, 6 and 9. Mice were killed on day 11 and the bladder weight was measured. Naive mice without tumor implantation (naïve), MB49 implanted-mice with no treatment (None) or vehicle (Veh) treated mice served as controls. *Statistically significant. 